\title{
Chronological occurrence of PI3KCA mutations in breast cancer liver metastases after repeat partial liver resection
}

\author{
Aldrick Ruiz ${ }^{1,2}$ (1) , Mylène Sebagh ${ }^{3,4}$, Raphaël Saffroy ${ }^{4,5}$, Marc-Antoine Allard ${ }^{2,4,5}$, Nelly Bosselut ${ }^{4,5}$, Giulia Hardoin ${ }^{4,5}$, \\ Julie Vasseur ${ }^{4,5}$, Jocelyne Hamelin ${ }^{4,5}$, René Adam ${ }^{2,6}$, Jean-François Morère ${ }^{4,7}$ and Antoinette Lemoine ${ }^{4,5,8^{*}}$
}

\begin{abstract}
Background: Liver metastases of breast cancer are frequent and can recur even after "complete/RO" resection in combination with systemic and hormonal treatments. The aim of this study was to analyze throughout repeat hepatectomies for liver metastases the evolution of PI3KCA gene mutational status.

Methods: All liver metastases nodules $(n=70)$ from 19 women who underwent at least 2 liver resections were reexamined. DNA extraction from archived tumoral tissue was performed and the major 'hot spot' mutations in the helical and catalytic domains of PI3KCA have been analyzed using Massarray platform (Agena Bioscience) based on allelic discrimination PCR amplification followed by sensitive mass spectrometry detection.

Results: The two major somatic hot spot PI3KCA mutations were found in 27 (38.6\%) nodules corresponding to 8 of the 19 patients (42\%). The frequency of women whose breast cancer liver metastases (BCLM) carries PI3KCA mutations increased from the first to the third hepatectomy. Tumors carrying PI3KCA mutations are significantly larger and more frequently observed when resections were RO compared to patients with no PI3KCA mutation.

Conclusion: PI3KCA mutations are frequently observed in BCLM and persist along with the recurrence. Their identification in circulating tumor cells should become a useful biomarker in the routine practice of breast cancer management to prevent tumor recurrence and overcome the problems of intra- and inter-tumoral heterogeneity of the current biomarkers,
\end{abstract}

Keywords: PI3KCA, Breast, Cancer, Liver, Metastases, Lineage, Evolution

\section{Introduction}

A significant proportion of breast cancer patients will eventually develop metastases (stage IV) with poor prognostic outcome [1-3]. Distant metastatic sites were identified as the brain, liver, lungs, and bones. Once metastatic disease is diagnosed, treatment is generally palliative and usually consists of anthracycline- or taxane-based regimes with or without hormonal or targeted therapeutic agents. This widely implemented palliative approach has yielded median survival ranging between 3 to 16 months [2-7]. For liver metastases, aggressive approaches adopted by experienced hepatobiliary centers, where systemic and

\footnotetext{
* Correspondence: antoinette.lemoine@aphp.fr

${ }^{4}$ Inserm UMR-S 1193, Université Paris-Sud Orsay, France

${ }^{5}$ AP-HP Hôpital Paul Brousse, Department Oncogénétique, Villejuif, France

Full list of author information is available at the end of the article
}

hormonal treatments for metastatic breast cancer are combined with surgical removal, has shown promising results in improving patient survival [8-12]. However, of the patients who undergo removal of breast cancer liver metastases, a portion still develops tumor recurrence in the liver.

Genomic profiling of tumor tissues has been increasingly used to understand and investigate the evolution of metastatic disease and alternative targets for breast cancer therapies $[13,14]$. There are several studies describing genotype profiling of breast tumors. Frequently altered genes are ErbB2, PI3K (phosphatidylinositol 3 kinase) pathways, TP53, BRCA1/2, and PTEN [15]. However, following common clinical practice there has few studies examining tumors beyond the usual point of first metastatic presentation or in recurrences after

(c) The Author(s). 2019 Open Access This article is distributed under the terms of the Creative Commons Attribution 4.0 International License (http://creativecommons.org/licenses/by/4.0/), which permits unrestricted use, distribution, and reproduction in any medium, provided you give appropriate credit to the original author(s) and the source, provide a link to the Creative Commons license, and indicate if changes were made. The Creative Commons Public Domain Dedication waiver (http://creativecommons.org/publicdomain/zero/1.0/) applies to the data made available in this article, unless otherwise stated. 
removal [16-19]. PIK3CA mutations have been reported to be present in over one-third of cases, with enrichment in the luminal and in human HER2-positive subtypes [19]. In human tumors or mammary epithelial cell lines, the two most common mutant alleles (H1047R and E545K) were found to activate PI3K signaling and to be involved in tumorigenesis and resistance to chemotherapy [20-23]. Therefore, the aim of this study was to analyze the chronology of major hotspot mutations in PI3KCA occurrence in a series of patients who underwent at least 2 liver resections for breast cancer liver metastases.

\section{Material and methods}

As part of treatment patients with recurrent breast cancer liver metastases can undergo repeat liver resection. This study is a retrospective case series experiment.

\section{Case selection}

Study size was based on convenient sample of the experience of a hepatobiliary center. All consecutive patients with breast cancer liver metastases (BCLM) who underwent at least two separate liver resections at our center between January 1985 and December 2012 were included in the study (Fig. 1). Patients were selected from our prospectively maintained institutional database, and each medical record was reviewed to update basic clinical and pathological data.

\section{Tissue samples}

Representative tumor samples of all nodules within each patient were collected and reviewed to examine genetic abnormalities. Hematoxylin-eosin-stained slides from tumors were assessed for the ratio percentage of tumor cells/sample area (non-tumor tissue, stroma of the tumor) by pathologists at our department. Three sections of $10 \mu \mathrm{m}$ thickness were obtained from the paraffin-embedded tissue containing at least $50 \%$ of tumor cells. Vascular or lymphatic invasion features were also analyzed. Immunohistochemistry analysis for hormonal receptors was conducted to analyze expression of hormonal receptors and HER2.

\section{DNA extraction}

DNA extraction was performed using the QIAmp DNA Mini kit (Qiagen, France), which provides silicamembrane-based nucleic acid purification [20].

\section{Mutations detection}

PIK3CA and HER2 mutations was analysed using a Massarray iPlex technology panel and Massarray online design tools (Agena Bioscience). The panel includes main exons (9 and 20) PIK3CA mutations (all mutations from 542 to 545-546-1047 codon), exon 20 HER2 insertions (codons 774-776) and exon 2 to 4 KRAS. The Massarray iPlex procedure involves a three-step process consisting of the initial PCR reaction, inactivation of unincorporated nucleotides by shrimp alkaline phosphatase and a single-base primer extension. Then, the products are nano-dispensed onto a matrix-loaded silicon chip (SpectroChipII, Ageno Bioscience) and finally, the mutations are detected by MALDI-TOF (matrix-assisted laser desorption-ionization-time of flight) mass spectrometry. Data analysis was performed using MassArrayTyper Analyzer software 4.0.4.20 (Agena Bioscience, Hamburg, Germany), which facilitates visualization of data patterns as well as the raw spectra. To allow detection of rare PIK3CA, HER2 or KRAS mutations, analysis of the whole exons was completed by High Resolution Melting analysis (HRM). PCR was performed in a 96-well plate with a $20 \mu \mathrm{L}$ volume including $50 \mathrm{ng}$ DNA, $2 \mathrm{mmol} / \mathrm{L}$ of each primer, $2.5 \mathrm{mmol} / \mathrm{L}$ of $\mathrm{MgCl} 2,4.7 \mu \mathrm{L}$ of water, and $10 \mu \mathrm{L}$ of LightCycler 480 HRM Master mix (Roche Diagnostics, France). The reaction mix was subjected to initial denaturation at $95^{\circ} \mathrm{C}$ for $10 \mathrm{~min}$,

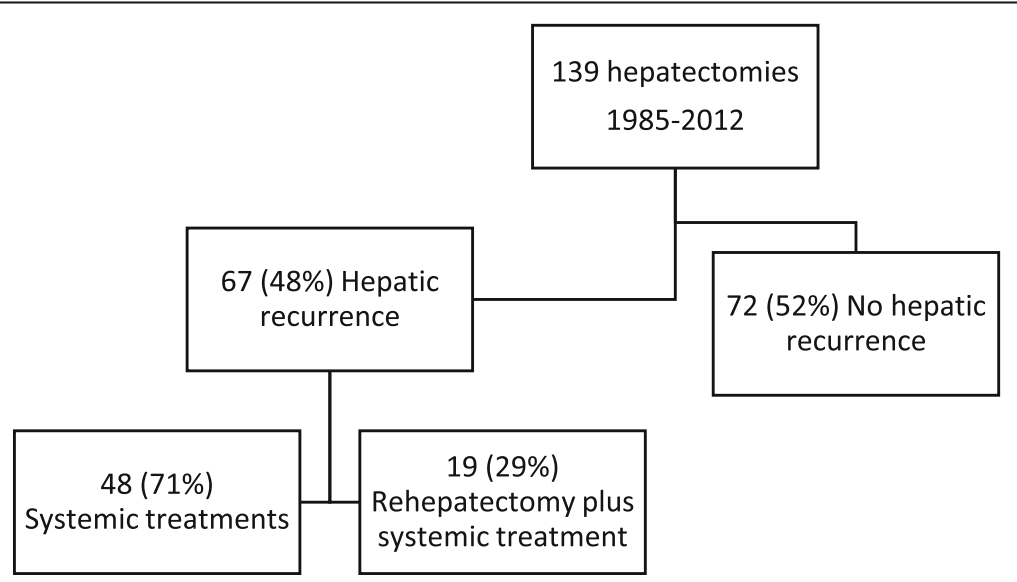

Fig. 1 Flowchart of the study population 
followed by 45 cycles of amplification consisting of denaturation at $95^{\circ} \mathrm{C}$ for $30 \mathrm{~s}$, annealing at $58^{\circ} \mathrm{C}$ for $30 \mathrm{~s}$, and extension at $72{ }^{\circ} \mathrm{C}$ for $30 \mathrm{~s}$. Melting was performed with a denaturation step at $95^{\circ} \mathrm{C}$ for $1 \mathrm{~min}$, followed by annealing at $40{ }^{\circ} \mathrm{C}$ for $1 \mathrm{~min}$ and a melt from $70{ }^{\circ} \mathrm{C}$ to 97 ${ }^{\circ} \mathrm{C}$ at a ramp rate of $0.03{ }^{\circ} \mathrm{C} /$ second with 18 acquisitions per second. LightCycler 480 Resolight Dye (Roche), a fluorescent dye that uniformly binds to the minor groove of double-stranded DNA in a nonsequence-dependent manner for melting analysis was used. In all experiments, positive and negative controls were included (Horizon diagnostics).

\section{Clinical data}

Hepatectomies were conducted in a tertiary center where data were available, extra information regarding the primary tumor was collected. Chronology of primary tumor, first liver metastasis, first hepatic resection, hepatic recurrences and repeat hepatectomies for each case were used for interval calculation.

\section{Statistical methods}

Categorical variables were compared between groups by the chi-square test or Fisher's exact test when appropriate and continuous variables were compared using the independent-sample t-test. All statistical analyses were performed with SPSS version 21.0 (SPSS Inc., Chicago, IL, USA).

\section{Results}

Patient samples

Between 1985 and 2012, 139 female patients underwent partial liver resection for breast cancer liver metastases at our institution (Fig. 1). Sixty-seven women (48\%) developed hepatic recurrence of which 19 patients (28\%) had subsequent second liver resections with curative intent. Four of them had a third hepatectomy. A total of 86 breast cancer liver metastases nodules were removed. Sixteen nodules were not available for molecular analysis due to insufficient tumoral cell content or inability to amplify DNA. High Resolution Melting and allelic discrimination PCR amplification using Massarray analyses were performed on samples originating from 70 nodules.

\section{Mutations discovered}

Overall, the two major somatic hot spot mutations in the helical and catalytic domains of PI3KCA in the breast cancer liver metastases were found in 27 (38.6\%) nodules corresponding to 8 of the 19 patients (42\%) (Fig. 2). No mutation in HER2 (exon 20) or KRAS (exon 2 to 4 ) were detected both by the High Resolution Melting analysis and allelic discrimination.

\section{Population characteristics}

Table 1 summarizes clinical characteristics of the patient population stratified by their corresponding hepatectomy. Mean maximum size of tumors removed during first hepatectomy was significantly larger in patients with

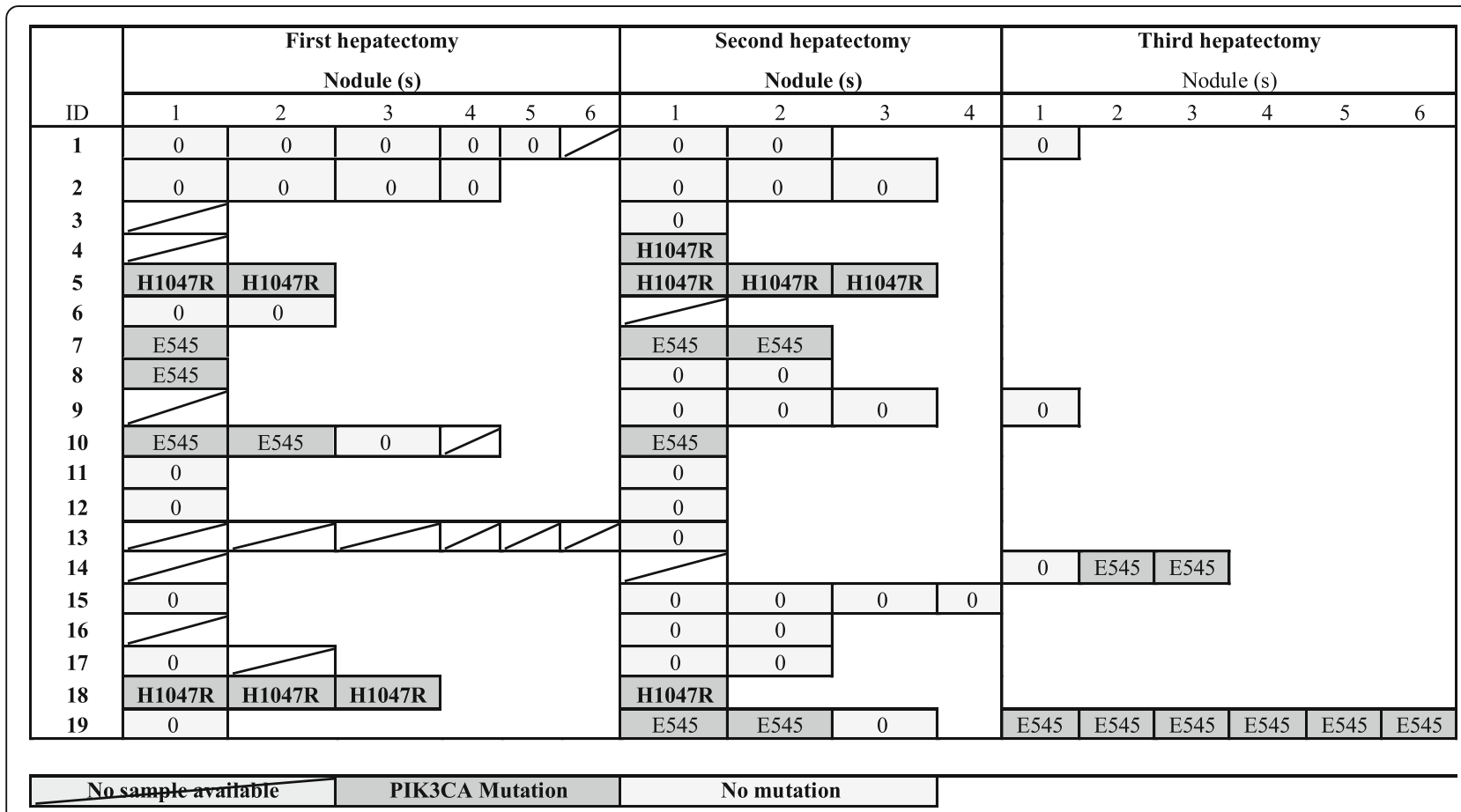

Fig. 2 Mutation detected in corresponding nodule after hepatectomies 
Table 1 Clinical characteristic according to PI3KCA mutation status

\begin{tabular}{|c|c|c|c|c|c|c|c|c|c|c|c|c|c|}
\hline \multirow[t]{3}{*}{ NN } & \multicolumn{4}{|c|}{ First hepatectomy } & \multicolumn{5}{|c|}{ Second hepatectomy } & \multicolumn{4}{|c|}{ Third hepatectomy } \\
\hline & \multirow{2}{*}{\multicolumn{2}{|c|}{$\begin{array}{l}\text { No Mutation } \\
N=8\end{array}$}} & \multirow{2}{*}{\multicolumn{2}{|c|}{$\frac{\text { Mutation }}{N=5}$}} & \multirow{2}{*}{\multicolumn{3}{|c|}{$\begin{array}{l}\text { No Mutation } \\
N=11\end{array}$}} & \multirow{2}{*}{\multicolumn{2}{|c|}{$\frac{\text { Mutation }}{N=6}$}} & \multirow{2}{*}{\multicolumn{2}{|c|}{$\begin{array}{l}\text { No Mutation } \\
N=2\end{array}$}} & \multirow{2}{*}{\multicolumn{2}{|c|}{$\begin{array}{l}\text { Mutation } \\
N=2\end{array}$}} \\
\hline & & & & & & & & & & & & & \\
\hline \multicolumn{14}{|l|}{ Hepatic metastases } \\
\hline Mean age at resection \pm SD Years & \multicolumn{2}{|c|}{$42 \pm 7$} & \multicolumn{2}{|c|}{$44 \pm 7$} & \multicolumn{3}{|c|}{$51 \pm 11$} & \multicolumn{2}{|c|}{$50 \pm 12$} & \multicolumn{2}{|c|}{$63 \pm 18$} & \multicolumn{2}{|c|}{$42 \pm 4$} \\
\hline $\begin{array}{l}\text { Mean interval between primary removal and liver resection } \\
+ \text { SD Months }\end{array}$ & \multicolumn{2}{|c|}{$42 \pm 20$} & \multicolumn{2}{|c|}{$47 \pm 37$} & \multicolumn{3}{|c|}{$43 \pm 21$} & \multicolumn{2}{|c|}{$46 \pm 33$} & & \pm 9 & 22 & \pm 9 \\
\hline Mean number of BCLM diagnosed \pm SD Distribution & $2 \pm$ & & $2 \pm$ & & & $2 \pm$ & & $2 \pm$ & & & & & \\
\hline Unilateral & 5 & $50 \%$ & 4 & $80 \%$ & & 9 & $82 \%$ & 4 & $67 \%$ & 1 & $50 \%$ & 1 & $100 \%$ \\
\hline Bilateral & 5 & $50 \%$ & 1 & $20 \%$ & & 2 & $18 \%$ & 2 & $33 \%$ & 1 & $50 \%$ & 0 & $0 \%$ \\
\hline Concomitant extra-hepatic disease & & & & & & & & & & & & & \\
\hline No & 10 & $91 \%$ & 4 & $80 \%$ & & 8 & $73 \%$ & 4 & $67 \%$ & 1 & $50 \%$ & 1 & $100 \%$ \\
\hline Yes & 1 & $9 \%$ & 1 & $20 \%$ & & 3 & $27 \%$ & 2 & $33 \%$ & 1 & $50 \%$ & 0 & $0 \%$ \\
\hline Chemotherapy before liver resection & & & & & & & & & & & & & \\
\hline No & 2 & $18 \%$ & 1 & $20 \%$ & & 0 & $0 \%$ & 1 & $17 \%$ & 0 & $0 \%$ & 0 & $0 \%$ \\
\hline Yes & 9 & $82 \%$ & 4 & $80 \%$ & & 11 & $100 \%$ & 5 & $83 \%$ & 2 & $100 \%$ & 2 & $100 \%$ \\
\hline Hormonal Therapy before liver resection & & & & & & & & & & & & & \\
\hline No & 8 & $73 \%$ & 2 & $40 \%$ & & 2 & $18 \%$ & 2 & $33 \%$ & 1 & $50 \%$ & 0 & $0 \%$ \\
\hline Yes & 3 & $27 \%$ & 3 & $60 \%$ & & 9 & $82 \%$ & 4 & $67 \%$ & 1 & $50 \%$ & 2 & $100 \%$ \\
\hline Targeted Therapy before liver resection & & & & & & & & & & ** & & & \\
\hline No & 7 & $64 \%$ & 4 & $80 \%$ & & 2 & $18 \%$ & 5 & $83 \%$ & 1 & $50 \%$ & 2 & $100 \%$ \\
\hline Yes & 4 & $36 \%$ & 1 & $20 \%$ & & 9 & $82 \%$ & 1 & $17 \%$ & 1 & $50 \%$ & 0 & $0 \%$ \\
\hline Histopathological characteristics & & & & & & & & & & & & & \\
\hline Mean maximum resected tumor size $\pm S D, m m$ & $17 \pm$ & & & -15 & * & 21 & 16 & & 12 & & +8 & & +11 \\
\hline Resection margin*** & & & & & & & & & & & & & \\
\hline RO & 8 & $89 \%$ & 3 & $60 \%$ & & 8 & $80 \%$ & 4 & $67 \%$ & 0 & $0 \%$ & 2 & $100 \%$ \\
\hline R1 & 1 & $11 \%$ & 2 & $40 \%$ & & 2 & $20 \%$ & 2 & $33 \%$ & 1 & $100 \%$ & 0 & $0 \%$ \\
\hline Microscopic intrahepatic invasion & & & & & & & & & & & & & \\
\hline No & 6 & $60 \%$ & 1 & $20 \%$ & & 7 & $64 \%$ & 2 & $33 \%$ & - & & 0 & $0 \%$ \\
\hline Yes & 4 & $40 \%$ & 4 & $80 \%$ & & 4 & $36 \%$ & 4 & $67 \%$ & - & & 2 & \\
\hline Cell surface receptors status & & & & & & & & & & & & & \\
\hline Estrogen & & & & & & & & & & & & & \\
\hline Negative & 0 & $0 \%$ & 2 & $40 \%$ & & 4 & $36 \%$ & 2 & $33 \%$ & 0 & $0 \%$ & 1 & $50 \%$ \\
\hline Positive & 8 & $100 \%$ & 3 & $60 \%$ & & 7 & $64 \%$ & 4 & $67 \%$ & 2 & $100 \%$ & 1 & $50 \%$ \\
\hline Progesterone & & & & & & & & & & & & & \\
\hline Negative & 5 & $63 \%$ & 4 & $80 \%$ & & 6 & $55 \%$ & 2 & $33 \%$ & 1 & $50 \%$ & 1 & $50 \%$ \\
\hline Positive & 3 & $38 \%$ & 1 & $20 \%$ & & 5 & $45 \%$ & 4 & $67 \%$ & 1 & $50 \%$ & 1 & $50 \%$ \\
\hline Her2/Neu & & & & & & & & & & & & & \\
\hline Negative & 6 & $75 \%$ & 4 & $80 \%$ & & 6 & $60 \%$ & 4 & $67 \%$ & 0 & $0 \%$ & 2 & $100 \%$ \\
\hline Positive & 2 & $25 \%$ & 1 & $20 \%$ & & 4 & $40 \%$ & 2 & $33 \%$ & 1 & $100 \%$ & 0 & $0 \%$ \\
\hline Differentiation & & & & & & & & & & & & & \\
\hline Well differentiated & 0 & $0 \%$ & 1 & $20 \%$ & & 1 & $14 \%$ & 2 & $40 \%$ & 1 & $50 \%$ & 0 & $0 \%$ \\
\hline Moderately differentiated & 5 & $71 \%$ & 4 & $80 \%$ & & 3 & $43 \%$ & 2 & $40 \%$ & 0 & $0 \%$ & 1 & $50 \%$ \\
\hline Poorly differentiated & 2 & $29 \%$ & 0 & $0 \%$ & & 3 & $43 \%$ & 1 & $20 \%$ & 1 & $50 \%$ & 1 & $50 \%$ \\
\hline
\end{tabular}


PI3KCA mutation compared to patients with no PI3KCA mutation $33 \mathrm{~mm}$ vs. $17 \mathrm{~mm}$ respectively $p=$ 0.07 . At the Second hepatectomy the proportion of patients treated with anti-HER2 targeted therapy is significantly higher in patients without PI3KCA compared to patients with PI3KCA mutation $82 \%$ vs. $17 \%$ respectively $(p=0.035)$. Timeline, anatomical location and extend of metastatic disease are highlighted for the presence of mutation and is presented in Table 2.

\section{Chronological occurence of PI3KCA mutation}

Four out of 5 patients with "Breast Liver Cancer Metastases" with PI3KCA mutations at the first hepatectomy, had the same mutation at the second hepatectomy. Three (16\%) women had de novo PI3KCA in their tumors at the second or third hepatectomy. Four patients received a third hepatectomy of which 2 had PISKCA mutations (one possible de novo and one recurrence). At the first, second and third hepatectomy, 38, 47 and $50 \%$ respectively of the patients for whom tumors were available had PI3KCA mutations (Fig. 2).

Of the 8 multinodular hepatectomies with PI3KCA mutation, the same mutation was found in all the nodules for 5 of them (62.5\%). For the 3 remaining hepatectomies, the PI3KCA mutation was observed in 2 out of 3 nodules.

\section{Discussion}

In our case series of patients who underwent repeat hepatectomies for breast cancer liver metastases, PIK3CA hotspot mutations were frequently observed in most of the nodules for multinodular tumors and persist along with the liver metastases recurrence. Their frequencies also increased along with hepatectomies. When examining the specific mutation H1047R or E545K, mutation remains the same within each patient over time.

The global frequency of PI3KCA mutations found in liver metastases in this series of patients is similar to those reported in sequencing studies in multiple cancers. PIK3CA mutations are present in approximately $30 \%$ of all breast cancers, with a higher frequency reported in oestrogene or progesterone positive tumors as well as in HER2-positive breast cancers [13-19]. In our series, almost all tumors express either HER2 or a hormone receptor, explaining the high frequency of PI3KCA gene mutations. To our knowledge, there are no data reporting neither frequencies of PI3KCA mutations in breast cancer liver metastases nor a specific gene signature including PI3KCA mutations. In the molecular classification of

Table 2 Clinical characteristics and presence of PI3KCA mutations

\begin{tabular}{|c|c|c|c|c|c|c|c|c|c|c|c|c|c|c|}
\hline \multirow[t]{2}{*}{ ID } & \multirow{2}{*}{$\begin{array}{l}\text { Year } \\
\text { Primary } \\
\text { tumor }\end{array}$} & \multirow[b]{2}{*}{ Margins } & \multicolumn{4}{|c|}{ First hepatectomy } & \multicolumn{4}{|c|}{ Second hepatectomy } & \multicolumn{3}{|c|}{ Third hepatectomy } & \multirow{2}{*}{$\begin{array}{l}\text { Survival } \\
\text { since } \\
\text { primary } \\
\text { (months) }\end{array}$} \\
\hline & & & $\begin{array}{l}\text { Interval } \\
\text { (months) }^{a}\end{array}$ & $\begin{array}{l}\text { Intra } \\
\text { hepatic } \\
\text { Location }\end{array}$ & xhep & Margins & $\begin{array}{l}\text { Interval } \\
\text { (months) }^{a}\end{array}$ & $\begin{array}{l}\text { Intra hepatic } \\
\text { Location }\end{array}$ & xhep & Margins & $\begin{array}{l}\text { Interval } \\
\text { (months) }^{a}\end{array}$ & $\begin{array}{l}\text { Intra hepatic } \\
\text { Location }\end{array}$ & xhep & \\
\hline 1 & 1989 & RO & 45 & $\mathrm{Bl}$ & No & - & 53 & $\mathrm{BI}$ & No & - & 21 & UL & No & 140 \\
\hline 2 & 1998 & R1 & 65 & UR & Yes & RO & 40 & UR & No & & & & & 142 \\
\hline 3 & 2002 & - & 22 & UR & No & RO & 57 & UR & No & & & & & 95 \\
\hline 4 & 1984 & - & 65 & & No & RO & 46 & $\mathrm{Bl}$ & No & & & & & 195 \\
\hline 5 & 1988 & RO & 27 & UL & No & R1 & 26 & UL & No & & & & & 127 \\
\hline 6 & 1998 & R0 & 49 & UR & No & RO & 38 & $\mathrm{Bl}$ & Yes & & & & & 112 \\
\hline 7 & 1992 & R0 & 46 & UR & Yes & RO & 28 & UL & No & & & & & 108 \\
\hline 8 & 2005 & $\mathrm{R} 1$ & 34 & UR & No & RO & 34 & UR & Yes & & & & & 93 \\
\hline 9 & 1988 & RO & 30 & UR & No & $\mathrm{R} 1$ & 34 & UL & No & $\mathrm{R} 1$ & 34 & $\mathrm{Bl}$ & Yes & 205 \\
\hline 10 & 1993 & RO & 56 & UL & No & $\mathrm{R} 1$ & 113 & UL & Yes & & & & & 182 \\
\hline 11 & 2000 & RO & 34 & UL & No & $\mathrm{R} 1$ & 36 & UL & No & & & & & 107 \\
\hline 12 & 1998 & RO & 27 & $\mathrm{Bl}$ & No & RO & 49 & UL & No & & & & & 120 \\
\hline 13 & 1999 & - & 17 & $\mathrm{Bl}$ & No & RO & 29 & $\mathrm{Bl}$ & Yes & & & & & 72 \\
\hline 14 & 1986 & RO & 82 & UL & No & RO & 40 & UL & No & RO & 28 & UR & Yes & 244 \\
\hline 15 & 1999 & - & 62 & & No & RO & 92 & UL & Yes & & & & & 157 \\
\hline 16 & 1997 & RO & 60 & UR & No & RO & 44 & UR & No & & & & & 145 \\
\hline 17 & 1992 & R0 & 42 & $\mathrm{Bl}$ & No & RO & 8 & UR & No & & & & & 75 \\
\hline 18 & 2003 & $\mathrm{R} 1$ & 10 & $\mathrm{Bl}$ & No & RO & 32 & $\mathrm{Bl}$ & Yes & & & & & 63 \\
\hline 19 & 1990 & RO & 36 & $\mathrm{Bl}$ & No & RO & 32 & UR & No & RO & 15 & UR & No & 93 \\
\hline
\end{tabular}

${ }^{\mathrm{a}}$ To previous event, xhep extra hepatic metastases, BI Bilobular, UL Unilateral Left, UR Unilateral Right, PI3KCA mutated tumors 
Hennecke et al., liver metastasis was most frequent in HER-2-enriched variety and PI3KCA mutations have also been enriched in HER-2 breast cancers [4]. We can observe a tendency for more PI3KCA mutated nodules between the first and second hepatectomies for tumors expressing these receptors.

The increase in the mutation rate along with hepatectomies can be considered as a marker of clonal evolution in favor of the selection of a dominant clone. In our study, mutations of PI3KCA show such an increase after each hepatectomy and especially a generalization within nodules for multinodular tumors. This increase may be due to malfunctions of the mechanisms for maintaining the integrity of the genome or its exposure to mutagenic agents and thus sign the resistance to treatments. We observe the expansion of mutations within nodules and at each hepatectomy highlighting a potential role of PI3KCA mutations as a marker of treatment resistance and expansion of clones bearing the PI3KCA anomaly. However, since the increase in the frequency of mutations is inversely correlated with the HER2 status of primary tumors that guided targeted therapy, PI3KCA mutations do not appear to be involved in the resistance mechanism of anti-HER2 therapies.

Once the oncogenic mutation is acquired, it can become a driver excluding generally other oncogenic mutations. It can then impact the tumor microenvironment and grow by promoting tumor angiogenesis. This is what we observe in our study. Indeed, tumors with a PI3KCA mutation are larger and trend to be associated with more tumor invasion of microvessels. This probably makes the tumors more aggressive. Similarly, the increase rate of PI3KCA mutations in the women who underwent several hepactectomies for tumor relapse even when liver resections were complete is in favor of the emergence of the clones carrying resistance mutations.

The persistence of PI3KCA mutations over time and despite one or two R0 hepatectomies, as well as the delay between 2 hepatectomies, mainly signify the presence of a reservoir of tumor cells in the form of dormant cells or stem cells [22]. These cells would preferentially carry the PI3K mutations conferring on them this property. They can also circulate in the bloodstream and be identified as prognostic and/or predictive markers to guide therapeutic decisions.

These findings raise more questions than answers. Common knowledge dictates that cancer progresses in steps $[23,24]$ and treatment strategies have been directed at the last step of "evolution". The basis of systemic palliative treatment has been based on trial and error and our findings raise the question whether a better strategy might be to base our strategies on tumor lineage. In other words, tumor cells might have a common origin but might have taken different evolutionary paths during time. A proposition could be to surgically remove and analyze all tumors to identify inter tumor "lineage" variation which in turn would lead to multi-lineage treatment strategies with the ultimate goal to eradicate all malignant cells.

Dan Frumkin et al., developed a way of reconstructing cell lineage trees from genomic variability caused by somatic mutations. This method was applied to cancer and for the first time a lineage tree of neoplastic and adjacent normal cells was reconstructed [25]. Other studies have also come to similar findings when examining chemotherapies effect using radiolabeling and imaging studies. Both methods support the idea of multi-lineage and genetic heterogeneity of metastases disease $[24,26]$.

This relatively small series study has some inherit limitation. There is no statistical power to make a definitive statement about clinical significance of our findings however these findings have not been presented before and can become the basis for further studies on the tumor heterogeneity and changes overtime. As a specialized center, the primary tumor tissue is usually not available for genetic studies which is important to complete the picture and lineage link. Furthermore, women with breast cancer liver metastases, usually present years after primary tumor discovery which makes it challenging to obtain primary tumor tissue and perform these genetic mutation detections.

\section{Conclusion}

In conclusion, PIK3CA mutations are frequently observed in breast cancer liver metastases and persist over time. The frequently observed mutations in PIK3CA that have been associated with resistance to chemotherapy, anti-HER2 or anti-estrogen therapies could be involved in the recurrence of liver metastases and might be a target in the future[27]. The identification of circulating tumor cells carrying PI3KCA should become a useful biomarker in the routine practice of breast cancer to prevent tumor recurrence but also to overcome the problems of intra- and inter-tumoral heterogeneity, as well as temporal, of the current biomarkers, which are hormonal receptor or HER2 expression measurements whose evolutions are not re-evaluated during treatments or in all metastatic sites.

\section{Abbreviations}

BCLM: Breast Cancer Liver Metastases; HER2: Human epidermal growth factor receptor; PIK3CA: Phosphatidylinositol-4,5-Bisphosphate 3-Kinase Catalytic Subunit Alpha

\section{Acknowledgments}

Not applicable

Funding

The Netherlands Organization for Scientific Research (NOW). Grant number: 017.009.053. 


\section{Availability of data and materials}

The datasets used and/or analysed during the current study are available from the corresponding author on reasonable request.

\section{Authors' contributions}

AR: Lead author, histology preparation. MS: Histology review and manuscript contributor and review. RS: Genetic analysis and manuscript contributor. MA: Tissue analysis and manuscript contributor. NB: Tissue analysis and manuscript contributor. GH: Genetic analysis and manuscript contributor. JV: Genetic analysis and manuscript contributor. JH: Genetic analysis and manuscript contributor. JM: Oncologist and study design. RA: Hepatic surgeon and study design. AL: Department supervisor, study design, genetic analysis interpretation, manuscript contributor. All authors read and approved the final manuscript.

\section{Ethics approval and consent to participate}

Ethics review is not required under French Law.

\section{Consent for publication}

Not applicable.

\section{Competing interests}

All authors certify that they have NO affiliations with or involvement in any organization or entity with any financial interest (such as honoraria; educational grants; participation in speakers' bureaus; membership, employment, consultancies, stock ownership, or other equity interest; and expert testimony or patent-licensing arrangements), or non-financial interest (such as personal or professional relationships, affiliations, knowledge or beliefs) in the subject matter or materials discussed in this manuscript.

\section{Publisher's Note}

Springer Nature remains neutral with regard to jurisdictional claims in published maps and institutional affiliations.

\section{Author details}

'Department of Surgery, University Medical Center Utrecht, Utrecht, The Netherlands. ${ }^{2}$ AP-HP Hôpital Paul Brousse, Centre Hépato-Biliaire, Villejuif, France. ${ }^{3}$ Department de Pathologie, AP-HP Hôpital Paul Brousse, Villejuif, France. ${ }^{4}$ Inserm UMR-S 1193, Université Paris-Sud Orsay, France. ${ }^{5}$ AP-HP Hôpital Paul Brousse, Department Oncogénétique, Villejuif, France. ${ }^{6}$ Inserm UMR-S 985, Université Paris-Sud Orsay, France. ${ }^{7}$ Department. Cancérologie, AP-HP Hôpital Paul Brousse, Villejuif, France. ${ }^{8}$ Departement of Oncogenetics, APHP, GH Paris-Sud, Hôpital Paul Brousse, Inserm UMR-S 1193, Université Paris-Saclay, 14 Avenue Paul Vaillant Couturier, 94800 Villejuif, France.

\section{Received: 15 April 2018 Accepted: 11 February 2019}

\section{Published online: 22 February 2019}

\section{References}

1. Jung SY, Rosenzweig M, Sereika SM, Linkov F, Brufsky A, Weissfeld JL. Factors associated with mortality after breast cancer metastasis. Cancer Causes Control. 2012 Jan;23:103-12.

2. Abuzallouf S, Motawy M, Thotathil Z. Baseline staging of newly diagnosed breast Cancer - Kuwait Cancer control center experience. Med Princ Pract. 2007;16(1):22-4.

3. Schuetz F, Diel IJ, Pueschel M, von Holst T, Solomayer EF, Lange S, et al. Reduced incidence of distant metastases and lower mortality in 1072 patients with breast cancer with a history of hormone replacement therapy. Am J Obstet Gynecol. 2007;196(4):342 e1-9.

4. Kennecke H, Yerushalmi R, Woods R, Cheang MCU, Voduc D, Speers CH, et al. Metastatic behavior of breast Cancer subtypes. J Clin Oncol. 2010 Jul 10; 28(20):3271-7.

5. Pogoda K, Niwińska A, Murawska M, Pieńkowski T. Analysis of pattern, time and risk factors influencing recurrence in triple-negative breast cancer patients. Med Oncol. 2013;30(1):388-96. Available from: https://doi.org/10. 1007/s12032-012-0388-4.

6. Berman AT, Thukral AD, Hwang WT, Solin L, Vapiwala N. Incidence and patterns of distant metastases for patients with early-stage breast cancer after breast conservation treatment. Clin Breast Cancer. 2013 Apr;13:88-94.

7. Follana P, Barrière J, Chamorey E, Largillier R, Dadone B, Mari V, et al. Prognostic factors in 401 elderly women with metastatic breast Cancer. Oncology. 2014;86(3):143-51.
8. Adam R, Aloia T, Krissat J, Bralet MP, Paule B, Giacchetti S, et al. Is liver resection justified for patients with hepatic metastases from breast cancer? Ann Surg. 2006;244:897-907 discussion 907-8.

9. Adam R, Chiche L, Aloia T, Elias D, Salmon R, Rivoire M, et al. Hepatic resection for noncolorectal nonendocrine liver metastases: analysis of 1,452 patients and development of a prognostic model. Ann Surg. 2006;244:524-35.

10. Ruiz A, Castro-Benitez C, Sebagh M, Giacchetti S, Castro-Santa E, Wicherts DA, et al. Repeat hepatectomy for breast Cancer liver metastases. Ann Surg Oncol. 2015;22(Suppl 3):S1057-66.

11. Ruiz A, Wicherts DA, Sebagh M, Giacchetti S, Castro-Benitez C, van Hillegersberg $\mathrm{R}$, et al. Predictive profile-nomogram for liver resection for breast Cancer metastases: an aggressive approach with promising results. Ann Surg Oncol. 2017 Feb;24:535-45.

12. Ruiz A, Sebagh M, Wicherts DA, Castro-Benitez C, van Hillegersberg R, Paule $B$, Castaing D, Vibert E, Cunha AS, Cherqui D, Morère JF, Adam R. Long-term survival and cure model following liver resection for breast cancer metastases. Breast Cancer Res Treat. 2018;170(1):89-100. PMID: 29464535. https://doi.org/10.1007/s10549-018-4714-1. Epub 2018 Feb 20.

13. Cejalvo JM, Perez-Fidalgo JA, Ribas G, Burgues O, Mongort C, Alonso E, et al. Clinical implications of routine genomic mutation sequencing in PIK3CA/ AKT1 and KRAS/NRAS/BRAF in metastatic breast cancer. Breast Cancer Res Treat. 2016 Nov;160:69-77.

14. Tobin NP, Harrell JC, Lovrot J, Egyhazi Brage S, Frostvik Stolt M, Carlsson L, et al. Molecular subtype and tumor characteristics of breast cancer metastases as assessed by gene expression significantly influence patient post-relapse survival. Ann Oncol. 2015;26:81-8.

15. Lee EY, Muller WJ. Oncogenes and tumor suppressor genes. Cold Spring Harb Perspect Biol. 2010;2:a003236.

16. Di Cosimo S, Baselga J. Phosphoinositide 3-kinase mutations in breast cancer: a "good" activating mutation? Clin Cancer Res. 2009 Aug 15;15: 5017-9.

17. Dunlap J, Le C, Shukla A, Patterson J, Presnell A, Heinrich MC, et al. Phosphatidylinositol-3-kinase and AKT1 mutations occur early in breast carcinoma. Breast Cancer Res Treat. 2010 Apr;120:409-18.

18. Kandula M, Chennaboina KK, Ys AR, Raju S. Phosphatidylinositol 3-kinase (PI3KCA) oncogene mutation analysis and gene expression profiling in primary breast cancer patients. Asian Pac J Cancer Prev. 2013;14:5067-72.

19. Yuan TL, Cantley LC. PI3K pathway alterations in cancer: variations on a theme. Oncogene. 2008 Sep 18;27:5497-510.

20. Allard MA, Saffroy R, de la Maisonneuve PB, Ricca L, Bosselut N, Hamelin J, Lecorche E, Bejarano MA, Innominato P, Sebagh M, Adam R, Morère JF, Lemoine A. Colorectal liver metastases are more often super wild type. Toward treatment based on metastatic site genotyping? Target Oncol. 2015; 10(3):415-21. https://doi.org/10.1007/s11523-014-0346-5.

21. Singh RR, Bains A, Patel KP, Rahimi H, Barkoh BA, Paladugu A, et al. Detection of high-frequency and novel DNMT3A mutations in acute myeloid leukemia by high-resolution melting curve analysis. J Mol Diagn. 2012 Jul;14:336-45.

22. Boros M, Moncea D, Moldovan C, Podoleanu C, Georgescu R, Stolnicu S. Intratumoral heterogeneity for Ki-67 index in invasive breast carcinoma: a study on 131 consecutive cases. Appl Immunohistochem Mol Morphol. 2017;25(5):338-40.

23. Nowell P. The clonal evolution of tumor cell populations. Science. 1976 Oct 1;194(4260):23-8.

24. Morandi L, Pession A, Marucci GL, Foschini MP, Pruneri G, Viale G, et al. Intraepidermal cells of Paget's carcinoma of the breast can be genetically different from those of the underlying carcinoma. Hum Pathol. 2003 Dec; 34(12):1321-30.

25. Frumkin D, Wasserstrom A, Itzkovitz S, Stern T, Harmelin A, Eilam R, et al. Cell lineage analysis of a mouse tumor. Cancer Res. 2008 Jul 15;68(14):5924-31.

26. Rijpkema M, Boerman OC, Oyen WJG. Tumor targeting using radiolabeled antibodies for image-guided drug delivery. Curr Drug Targets. 2015;16(6): $625-33$.

27. Sobhani N, Roviello G, Corona SP, Scaltriti M, lanza A, Bortul M, et al. The prognostic value of PI3K mutational status in breast cancer: a meta-analysis. J Cell Biochem. 2018;1 19(6):4287-92. Available from: https://doi.org/10.1002/ jcb.26687. 